\title{
STUDENT ACCEPTANCE OF LEARNING WITH TABLETS IN A HISTORY MUSEUM
}

\author{
Alan J. Wecker, Merav Yosfan, Billie Eilam and Joel Lanir \\ University of Haifa \\ Mount Carmel, Haifa, Israel
}

\begin{abstract}
This paper examines early results of an experiment in students' user experience for in context learning in a museum with a mobile device. We examine 3 conditions. The first is a paper worksheet (approximately 50 pages) vs two types of mobile application (approximately 25 screens). The second set (both mobile applications) compares a constructivist to an informative educational approach. The students preferred the mobile app over the printed worksheet. Students also found the informative approach preferable to the constructivist approach. In the future we will examine which approach had better learning results and delve deeper into examination of the learning process.
\end{abstract}

\section{KEYWORDS}

Mobile Museum Learning

\section{INTRODUCTION}

One way to enhance student's engagement in humanity-oriented museums is by using electronic mobile devices. Mobile devices, such as smart phones, are ubiquitous today and have become widely available and used. Adults and children alike use mobile phones throughout their daily lives to communicate, organize their daily activities, play, and also learn. Such individual devices may provide customized and personalized learning experiences, building on user's own understanding and making their own choices (Schwartz \& Arena, 2013), at their own pace. At the museum, mobile technologies pose both an opportunity and a problem. A multimedia mobile museum guide, e.g., can provide museum visitors with a wide variety of novel and important services. The visitor can receive personalized adaptive information from a vast amount of content sources that can suit his or her personal needs at a particular time. Information can be tailored according to the visitor's learning abilities and preferences (Ardissono et al., 2011). However, a mobile guide as the main interpretive option at the museum can also be problematic. It may focus the visitor's attention on the mobile device rather than on the museum exhibits. Furthermore, for small groups, it might isolate the visitors from their peers, effectively dissocializing the group (Grinter et al., 2002; Lanir et al., 2013).

In order to understand if and how the use of mobile technologies can enhance informal learning at the museum, we first need to characterize the existing mobile applications in such an environment. The integration of mobile devices as tools to support museums has become well established in recent years (Economou \& Meintani, 2011). Many mobile museum guides, i.e., classical audio guides or more advanced multimedia guides, are information-based, which means they have been designed to provide context-specific information presented in an information-centered way. Context is often achieved by utilizing location-based services (using QR codes or various sensors), while information is mostly limited to audio, text, images or short video-presentations providing details on nearby exhibits (e.g. Lanir et al., 2013). While these kind of guides may be beneficial for an individual adult visitor, being able to provide relevant and sometimes personalized information and services, they may not be ideal for children or small groups. Children arriving to museums at school trips, or individually with their parents, often require a more engaging form of presentation, especially in humanity type museums such as history museums.

A different approach for the design of mobile learning takes an activity-based approach (as opposed to a guide) that includes interactive inquiry learning and problem solving. In this approach, visitors need to solve some puzzles, find items (e.g., a treasure hunt) or actively produce their own interpretations. This is based on 
the constructivist epistemology that individuals are active learners and must construct knowledge for themselves (Schunk, 2004). A meaningful learning therefore, involves the granting of meaning to new acquired information by relating it to existing knowledge. Such a learning mode requires individuals' high engagement with meaningful tasks, while actively processing, interpreting and making sense of the information. Retention and deep understanding enables transfer and future use of this newly constructed knowledge in similar situations. In addition, the ability to construct several such connections to different but relevant bodies of existing knowledge or to adaptively re-assemble pieces of knowledge to fit a particular need in a complex context (like a museum) and ill-defined domains (like history), ensure the development of cognitive flexibility and this knowledge being active and used (Spiro \& Jehng, 1990). Several works have aimed at designing and implementing such mobile museum guides, for example, by using various games, quizzes and puzzles (see Mortara et al., 2014, for a survey). Other works, used a more direct approach, supporting collaborative enquiry work at the museum using the mobile phone which later can be used at home or in class (Vavoula et al, 2009).

\section{BACKGROUND}

Museums are one of the primary sites of informal learning (Bamberger \& Tal, 2007; Crane, 1994; Wood \& Latham, 2011). Museum learning complements formal learning at school by deepening and expanding school knowledge; relating to and presenting authentic objects (Bitgood, 1989); providing concrete ways for the assimilation of complex concepts and their comprehension (Wright, 1980); and applying multimodal presentation modes - visual, auditory and/or haptic, thereby promoting individuals' ability to observe and understand world phenomena (Wood \& Latham, 2011). Museum learning is fundamentally different in several aspects from formal learning: the temporal - being for a short time duration; the modularity - requiring no continuity; and the affect - being primarily based on curiosity, intrinsic motivation, selection and self-control (Bamberger \& Tal, 2007). Museum learning occurs through interactions involving personal, socio-cultural, and physical contexts, which create the foundation for the learning processes (Falk \& Dierking, 2000).

Studies investigating children's' learning in museums were conducted mostly in science museums, aquariums, and zoos and have focused on family visits (e.g., Bamberger \& Tal, 2007). Museums presenting information in the varied humanities domains were rarely investigated and knowledge regarding informal learning processes, their processes characteristics, and ways for improving them, are still mostly absent. The inherent importance of childrens' visits to such museums, especially along their school years, can't be underestimated. History museums for example, enable the children direct involvement with "real" objects from the past and raise their awareness of these objects relations to the present (Rosenzweig, 2000); reinforce children's history knowledge and related thinking skills; encourage children to deepen their life-long learning; and support history understanding as a subjective product influenced by economic, social and political factors (Marcus \& Levine, 2011).

\section{METHODOLOGY}

In order to better understand mobile-based learning strategies, we compared three options for informal learning at the museum. Through in-depth observations as well as questionnaires and interviews, we examine and compare students' learning, engagement, and communication patterns, when using the three options.

The study applies the naturalistic paradigm, suitable particularly for examining learning in informal educational environments. This paradigm describes participants' behaviors as they transpire and relates them to the environment in which they are observed. In addition, it allows observation of visitors' behavior without affecting the informal nature of their learning experience. To collect data, we use both quantitative and qualitative methods (microphones, video cameras, screen recordings). The qualitative method focuses on understanding the dynamics of isolated events, in order to achieve a more generalized understanding while the quantitative one enables comparing different conditions and knowledge of specific issues, and allows for inferences and generalization. 
The study includes 44 students learning in three 7th grade classrooms. Students' ages (12-13 years old) assures children's sufficient skills to cope with the museums' texts and labels. Moreover, 7th grade children's awareness of the importance of dates is already developed and they can link dates with their own background knowledge regarding the period's events (Brophy \& Vansledright, 1997).

The study uses a between-subject design, in which each student is assigned to one of the three experimental conditions. All three conditions relate to the same information and exhibits at the same cognitive level and use an activity based guide (These activity-centered applications support learning while performing various activities based on a question and answer approach in front of the exhibits).

1. Constructivist printed worksheet/guide. In this condition, Students get printed information with photos and texts (the same information as the audio in the video of the other conditions) and use assignment sheets with a pencil, that supports the interactive activities of the cognitive-activity type in front of particular exhibits/presentations. (approximately 50 pages)

2. Informative mobile worksheet. The students get short videos presenting them with information about the exhibits. The design of these activities is aimed at enhancing the recall and summation of the information; based on a series of questions and answers activities (with many multiple-choice type questions). (approximately 25 screens).

3. Constructivist mobile worksheet. The students get the same set of short videos presenting them with information about the exhibits. The design of these activities is aimed at enhancing the integration of information acquired into a coherent body of knowledge, based on the findings that mental engagement with the exhibits promotes learning. These are mainly based on answers to questions that the students must formulate by typing in answers to thought provoking questions. (approximately 25 screens).

\section{RESULTS}

We present here initial results of the user experience questionnaire of the three conditions (Table 1). The questionnaire used a 7-point Likert scale with the value of 1 meaning agree that it possess trait to an extreme degree and 7 meaning agree that it doesn't possess trait to an extreme degree.

Results show that printed guide was rated as least attractive and least efficient out of the three guides. All three guides were considered easy to use, with the mobile guides considered more interesting and more novel than the printed guide. Also, the mobile guides were considered clearer and more organized than the printed version. Looking at the negatively framed results we see that the informative was considered less annoying, less inefficient and less unfriendly (i.e., the friendliest). The printed guide was considered more boring and uninteresting.

Table 1. User experience questionnaire for the three types of guides used in the museum

\begin{tabular}{|l|r|r|r|r|r|r|r|r|r|}
\hline & \multicolumn{3}{|c|}{ Constructivist } & \multicolumn{3}{|c|}{ Informative } & \multicolumn{3}{c|}{ Printed } \\
\hline & $\mathrm{N}$ & Mean & Std. Dev & $\mathrm{N}$ & Mean & Std. Dev & $\mathrm{N}$ & Mean & Std. Dev \\
\hline Attractiveness & 14 & 2.21 & 1.57 & 15 & 1.47 & 1.18 & 12 & 2.75 & 1.54 \\
\hline Efficiency & 14 & 1.64 & 1.59 & 15 & 1.73 & 1.16 & 12 & 2.92 & 1.50 \\
\hline Ease of use & 14 & 1.29 & 1.72 & 15 & 1.00 & 0.92 & 12 & 1.83 & 1.26 \\
\hline Control & 14 & 1.29 & 1.26 & 15 & 1.07 & 0.96 & 12 & 2.75 & 1.81 \\
\hline Interesting & 14 & 2.57 & 1.86 & 15 & 2.27 & 1.75 & 12 & 3.08 & 1.31 \\
\hline Novelty & 14 & 1.43 & 1.82 & 15 & 1.87 & 1.59 & 12 & 2.17 & 1.74 \\
\hline Clear & 13 & 1.92 & 1.32 & 15 & 1.60 & 0.91 & 12 & 3.67 & 1.87 \\
\hline Organized & 13 & 2.08 & 1.32 & 14 & 2.29 & 1.77 & 11 & 4.64 & 2.15 \\
\hline & & & & & & & & & \\
\hline Annoying & 14 & 4.86 & 1.91 & 15 & 6.00 & 1.06 & 12 & 4.33 & 1.69 \\
\hline Inefficient & 13 & 6.23 & 1.42 & 15 & 5.33 & 2.12 & 11 & 5.73 & 1.00 \\
\hline Not useful & 13 & 5.62 & 1.60 & 15 & 5.53 & 1.88 & 11 & 5.55 & 1.03 \\
\hline Unfriendly & 14 & 5.43 & 1.74 & 14 & 6.43 & 0.64 & 12 & 5.33 & 0.77 \\
\hline Unpleasant & 11 & 5.27 & 1.61 & 15 & 6.07 & 1.53 & 12 & 5.25 & 1.05 \\
\hline Not understandable & 13 & 6.38 & 1.04 & 15 & 6.60 & 0.63 & 12 & 5.75 & 1.48 \\
\hline Hard to learn & 13 & 6.54 & 1.12 & 15 & 6.53 & 0.83 & 11 & 6.00 & 0.89 \\
\hline Complicated & 13 & 6.38 & 1.12 & 15 & 6.60 & 0.63 & 12 & 5.58 & 0.99 \\
\hline Unpredictable & 13 & 5.62 & 1.12 & 15 & 6.60 & 0.63 & 12 & 4.17 & 1.94 \\
\hline Boring & 13 & 4.69 & 1.93 & 15 & 4.47 & 2.35 & 12 & 3.50 & 1.93 \\
\hline Uninteresting & 13 & 4.77 & 2.12 & 15 & 4.60 & 2.47 & 12 & 4.00 & 1.80 \\
\hline
\end{tabular}




\section{CONCLUSION AND FUTURE RESEARCH}

Summarizing the results, it seems there was an overall preference of the students for the informative guide, while the printed handouts were least preferred. We expected the printouts to be least preferred, mostly because of the novelty effect and since younger students often like technology as a mediator for learning. However, the preference of the informative guide over the constructivist one is surprising for us, and needs further investigation into the observational data in order to explain. A possible explanation is that constructivist methodology called for students to formulate written answers to questions in order to assimilate, while the informative guide allowed for more multiple choice items.

These are early results which show a clear direction for student acceptance preferences. We plan to have another three classes with about 80 students from another school using the three condition. In addition, we have started to analyze student's knowledge questionnaires as well as their recorded audio and video to investigate and compare learning accomplishments and group behavior between the three conditions.

\section{REFERENCES}

Ardissono, L., Kuflik, T., \& Petrelli, D. (2011). Personalization in cultural heritage: The road travelled and the one ahead. User Modeling and User-Adapted Interaction, 22(1), 1-27.

Bamberger, Y., \& Tal, T. (2007). Learning in a personal context: level of bechoice in a free choice learning environment in science and natural history museums. Science Education, 91(1), 75-95.

Bitgood, S. (1989). School field trips: an overview. Visitor Behavior, 4(2), 3-6.

Brophy, J., \& Vansledright, B. (1997). Teaching and learning history in elementary schools. New York: Teachers College Press.

Crane, V. (1994). An introduction to informal science learning and research. In V., Crane, M., Chen, S., Bitgood, B., Serrell, D., Thompson, H., Nicholson, F., Weiss, \& P., Campbell, Informal science learning: what the research says about television, science museums and community-based projects (pp.1-14). U.S.: Research Communication Ltd.

Economou, M., \& Meintani, E. (2011). Promising Beginning? Evaluating Museum Mobile Phone Apps.

Falk, J. H., \& Dierking, L. D. (2000). Learning from museums - visitor experiences and the making of meaning. New York and Oxford: Rowman \& Littlefield Publishers, Inc.

Grinter, R. E., Aoki, P. M., Szymanski, M. H., Thornton, J. D., Woodruff, A., \& Hurst, A. (2002). Revisiting the visit: Understanding how technology can shape the museum visit. Proceedings of the 2002 ACM Conference on Computer Supported Cooperative Work, 146-155.

Lanir, J., Kuflik, T., Dim, E., Wecker, A. J., \& Stock, O. (2013). The influence of a location-aware mobile guide on museum visitors' behavior. Interacting with Computers, 25(6), 443-460.

Marcus, A. S. \& Levine, T. H. (2011). Knight at the museum: learning history with museums. The Social Studies, 102(3), 104-109.

Mortara, M., Catalano, C. E., Bellotti, F., Fiucci, G., Houry-Panchetti, M., \& Petridis, P. (2014). Learning cultural heritage by serious games. Journal of Cultural Heritage, 15(3), 318-325.

Schunk, D. H. (2004). Learning theories: An educational perspective (4th ed., Chap. 7, pp. 285-328). Upper Saddle River, NJ: Pearson, Merrill Prentice Hall.

Schwartz, D. L., \& Arena, D. (2013). Measuring what matters most: Choice-based assessment in the digital age. The John D. and Catherine T. MacArthur Foundation Reports on Digital Media and Learning. Cambridge, MA: MIT Press.

Spiro, R., Jehng, J. (1990). Cognitive flexibility and hypertext: Theory and technology for the nonlinear and multidimensional traversal of complex subject matter. In Nix, D., Spiro, R. (Eds.), Cognition, education and multimedia: Exploring ideas in high technology (pp. 163- 205). Hillsdale, NJ: Lawrence Erlbaum Associates, Inc.

Vavoula G., Sharples M., Rudman P., Meek J. \& Lonsdale P. (2009) Myartspace: design and evaluation of support for learning with multimedia phones between classrooms and museums. Computers and Education 53, 286-299.

Wood, E., \& Latham, K., F. (2011). The thickness of things - Exploring the curriculum of museums through phenomenological touch. Journal of Curriculum Theorizing (27), 51- 65.

Wright, E. L. (1980). Analysis of the effect of museum experience on the biology achievement of sixth-graders. Journal of Research in Science Teaching, 17(2), 99-104. 